\title{
Techniques in Utilizing Remote Sensor Technology for Precision Crop Production by Farmers as Climate Change Adaptation Strategy in Nigeria
}

\author{
Florence 0. Ifeanyieze1, Michael E. Ikehi², Edward Isiwu ${ }^{3}$ \\ Agricultural Unit, Department of Vocational Teacher Education, University of Nigeria, Nsukka, Nigeria \\ Email: floraoby2001@yahoo.com, ikejidon1@yahoo.com, visiontrackltd@gmail.com
}

Received 2 November 2014; revised 17 November 2014; accepted 4 December 2014

Copyright (C) 2014 by authors and Scientific Research Publishing Inc.

This work is licensed under the Creative Commons Attribution International License (CC BY). http://creativecommons.org/licenses/by/4.0/

(c) (i) Open Access

\begin{abstract}
This paper focuses on techniques in utilizing remote sensor technology for precision crop production by farmers as climate change adaptation strategy in Nigeria. Descriptive survey research design was adopted for the study and was carried out between August 2013 and May 2014. The findings of the study revealed that 32 items were needed by farmers in utilizing sensory technology for precision crop production. The study recommended that the 32 items identified by the study should be utilized by extension agent in teaching the farmers the use of sensor technology for precision crop production while the farmers should make themselves available for the training.
\end{abstract}

\section{Keywords}

Remote Sensor Technology, Climate Change, Adaptation, Precision Farming Crop Production

\section{Introduction}

In every part of the world, farmers engage in crop production with the aim of providing food, income, raw materials and foreign exchange among others for the citizens. Crop production is the act of cultivating the soil in order to provide food and other materials for man and industrial uses. Crops grown require soil nutrients and water in addition to sunlight to derive the photosynthetic process so as to produce edible products for man's use. Crop production is climate sensitive with outdoor production activities that depend largely on particular levels of weather conditions. This means that crop production is one of the most sensitive agricultural sectors to climate change. 
Climate change is the significant and lasting variation in the statistical properties of the average weather condition when considered over long periods of time, regardless of cause [1]. Climate change refers to the variation in the average weather condition attributed directly or indirectly to natural events and human activities which alter the composition of the atmosphere over a period of time. Climate change affects crop production in a number of ways, for example, it leads to variation in the rainfall pattern, altering soil composition and increasing pests and disease migration [2] [3]. Though some crops might respond favorably to increased atmospheric weather conditions, growing more vigorously and using water more efficiently, higher temperature and change in rainfall patterns often alter areas where crops grow best and affect the makeup of natural plant communities [4]. Weather-related events (like long-lasting drought) add further complexity to the science of crop farming, resulting to shortage of food supply and consequently leading to frequent rising commodity prices [5]. There is need for farmers to seek for alternative means of enhancing their productivity through certain adaptation strategies.

Adaptation is the adjustment in natural or human systems in response to actual or expected climate stimuli or their effects [1]. Adaptation moderates harm and exploit beneficial opportunities inherent in a system. In crop production, certain agricultural ICT tools and gadgets (technologies) have been developed for precision farming despite climate change challenges.

Precision farming refers to information and technology-based agricultural management system to improve crop production efficiency by adjusting farming inputs to specific conditions within each area on a field [6]. Precision farming in crop production is the application of exact farming technologies to manage spatial and temporal variability for the purpose of improving crop performance and environmental quality [7]. Precision farming has become established due to advances in technology which enable accurate geo-referencing, real-time data acquisition, sensing, telemetric and variable rate application of inputs. Precision farming (PF) in crop production uses extensive data from a farmer's field and the surrounding region to help predict weather conditions and optimize operations [5]. For effective collection and analysis of relevant crop cultivation information, precision farming in crop production employs the services of agro-based remote/sensory technologies.

Remote sensing technology (RST) refers to the science of wirelessly observing and obtaining information on crop and soil characteristics using devices attached to aircraft, satellite, and agricultural equipment such as tractor [8] [9]. The sensors are made up of electronic probes and optical scanners that detect changes in the soil and surrounding environment. Remote sensors vary in the type of platform they are mounted, based on light source, spatial and spectral resolution. Remote sensors are classified as passive or active depending on the light source. Passive sensors measure the amount of sun energy reflected from the objects [10]. Passive sensors rely on sunlight, thereby limiting recording to the time when the cloud cover is minimal and the sun is illuminating the target area. These restrictions often limit data collection around noon to maximize available sunlight. Passive sensors are mounted on satellites (Land sat or Quick Bird) or airplanes [10]. In contrast to passive sensor, active sensors use their own modulated light at defined or fixed wavelengths. The sensor illuminates the object and uses photodiodes to measure the portion of light that is reflected [10]. A primary advantage of active sensor over passive is its ability to obtain measurements at any period, regardless of the time of the day or season in addition to eliminating the effects of sun angle and cloud cover. Active sensors are mounted on satellites (Radar sat) or ground vehicles (Green Seeker or Crop Circle).

RST can provide useful information for many crop management decisions, including detection of nutrient or water deficiencies and excesses in the soil, damages caused by insects, weeds, or diseases in various portions of the cultivated fields. RST obtains information about an object (crop or soil) without directly contacting it. Data collected can range from a simple colour photograph to the crop’s emission of electromagnetic energy [9]. Sensor data can provide farmers real-time information regarding their crop condition, allowing them to respond and make corrective or other management decisions to maximize production. Using a combination of sensors such as temperature, light and humidity, helps the farmer detect risks of frost/drought, possible plant pests/diseases and establish watering requirements based on soil dampness [3]. With the RST, data can be collected for an entire field as compared to traditional scouting methods which only provides single point or partial field coverage while data collected over multiple dates during the season allows farmers to monitor trends in crop progression and manage cultivation of crop in addition to monitoring the exact conditions in which the plants are growing from the comfort of homes [9]. The objectives of smart (RST) agriculture among others is to help control conditions and closely monitor performance of crops, where the smallest amount of change in climate can affect the final outcome, and to determine the best conditions for each crop, by comparing the data obtained during the 
best harvests [3].

Remote-sensory technology has a variety of applications, including environmental monitoring, site-specific agronomic management (SSM), land cover classification, climate- and land-use-change detection, and drought monitoring [10]. The ability of a remote sensor to detect subtle differences in vegetation makes it a useful tool for quantifying within-field variability, evaluating crop growth, and managing fields based on current conditions that may be overlooked using typical ground-based visual scouting methods during crop cultivation. While collecting real-time data on weather, soil, health of crops and air quality is important, it is also necessary to apply precision in crop harvesting to reduce damage and loss. To help cope with the trending resultant events of climate change and to generate enough food to meet the ever-growing demands of a growing global population for food, crop production needs to embrace smarter farming methods through the use of technologies such as agriculturally applicable sensor technology.

Using RST in PF will revolutionize the data collection in agricultural field, support the highly sought after automated agriculture system (AAS) which requires intensive sensing of environmental conditions at the ground level and rapid communication of the raw data to a local or remote server where there is the availability of computational and storage power, the identification of pests in the crops, drought or increased moisture, decision making, while the control of farm equipment is done in real time using automated actuation devices [11]. Automated actuation devices (forming Remote Sensor and Actuator Network-RSAN) like sprinklers, foggers, valvecontrolled irrigation system, harvesters and others, can be used to control irrigation, fertilization and pests in order to offset the adverse conditions [11].

The most important step in PF is the generation of maps of the soil with its characteristics [11]. These included grid soil sampling ( $\mathrm{pH}$, moisture, electrical conductivity and temperature), yield monitoring, and crop scouting. The strategically positioned sensors collect data in the form of electronic computer databases which gives birth to the Geographic Information System (GIS) for statistical analyses of data, to determine variability of agricultural land with respect to its properties [11]. An effective method used to easily interpret remote sensing data is calculating vegetation indices-VI [10]. VIs has been widely used to assess vegetation condition, cover, and growth, as well as evaluate canopy attributes such as leaf area index (LAI) and plant height. VI values indicate differences in vegetation condition or amount. It is necessary to determine the total number of sensory devices required to be deployed per ha of cultivatable land while considering planting density. Closed loop control ability (automation) as well as adaptability (reconfiguration) for different scenarios and sensor nodes is needed for the field operations [11]. Each of these scattered sensor nodes has the capability to collect and route data either to other sensors or back to an external base station(s) [11]-[13]. The base station is made capable of connecting the sensor network to an existing communications infrastructure or to the Internet where a user can have access to the reported data [14]. However, operational techniques are required to be transmitted to the farmers for incorporation of RST into farming by the extension agent whose responsibility is to teach farmers the techniques in utilizing new technology in farming. These extension agents were trained by lecturers of Agriculture in the universities to make them competent in identification of farmers' problems for solution. These extension agents and lecturers are knowledgeable in innovation that can be transmitted to the farmers for enhanced production especially in the use of sensory technology for precision farming.

In Nigeria, many farmers detect presence of draught, pests and diseases and plant-water requirement through scouting method. This traditional method provides single point coverage which does not permit farmers to know the exert soil and plant conditions in addition to preventing them by monitoring trends in the production for effective crop management decisions. It was also observed that despite farmers' effort to use different means for increased crop production in the country, occurrence of irregular and non-predictive rainfall pattern and sunshine hours continued to lower harvests of cassava, maize, melon and yam with at least $2.5 \%$ decline of harvests per annum [15]. Apart from loss of produce during cultivation, about half of the food produced is never consumed due to inefficiencies in the harvesting of crops [5]. Studies showed [16]-[18] that the world's population is expected to nearly double by 2050 while food supply is unlikely to follow the same pattern even by doubling the area under cultivation [3], due to the impact of climate change; there is need for continued crop production to meet the needs of the teaming population through the use of sensory technology. This means that in order to ensure high productivity, farmers must utilize different technologies (devices, machines or equipment) in production process to provide arable crops like cassava, cowpea, maize yam and others. However, the knowledge of the Graphical User Interface of the sensor technology application is needed on the side of the farmers to monitor and control scenarios, and instruct commands for (remote) decision on the farm. It was therefore based on this 
scenario that this study was initiated to identify the techniques in utilizing sensor technology so that the extension agents could use it as a training package for teaching farmers for precision crop production in the country; hence the study. The major purpose of this study was to identify techniques needed in utilizing remote sensor technology for precision crop production by farmers. Specifically the study sought to identify:

1) Planning techniques needed in utilization of sensor technology in crop production;

2) Operation techniques of sensory technology.

\section{Methodology}

This study adopted survey research design and was carried out in Nigeria between August 2013 and May 2014. The population for this study was 352 made up of 52 lecturers of agriculture from federal universities and 300 extension agents from ADP offices in Nigeria. A 32 item structured questionnaire identified from literature reviewed for the study was used to collect data from the respondents. Each questionnaire item was assigned a 4 response options of Highly Needed $(\mathrm{HN})=4$, Averagely Needed $(\mathrm{AN})=3$, Slightly Needed $(\mathrm{SN}=2)$ and Not Needed $(\mathrm{NN})=1$. The questionnaire items were face validated by 3 experts; two lecturer of agriculture from Enugu State University of Science and Technology (ESUT) Enugu and one extension officer from Imo State Agricultural Development Project (ADP) office. The Cronbach alpha method was used to determine the internal consistency of the items and a coefficient of 0.87 was obtained. The researchers collected the data with the help of eight assistants who were selected based on their familiarity with the study area. The respondents were requested to check the level to which each items was required with the aim to help develop a stepwise techniques that could be used as a training package for the farmer in the utilization of sensor technology. Out of 352 copies of the questionnaire administered, 327 (49 from lecturers and 278 from extension agents) were returned and used for data analysis.

The data collected for the study were analyzed using weighted mean to answer the research questions. In order to take decision on the needed item, real limit of numbers were assigned to each item thus: Highly Needed $($ HN 4) $=3.50$ - 4.49; Averagely Needed $($ AN 3) $=2.50$ - 3.49; Slightly Needed $($ SN 2) $=1.50-2.49$; Not Needed (NN 1) $=1.00-1.49$. So any item with a mean value within the real limit as indicated was interpreted accordingly as; Highly Needed (HN), Averagely Needed (AN) or Slightly Needed (SN) whereas any item with a mean value less than 1.50 was interpreted as Not Needed (NN). The standard deviation was used to determine the closeness of the respondents from the mean. Any item with a standard deviation of 1.96 or below indicated that the respondents were close to the mean and to one another in their responses while any item with a standard deviation above 1.96 showed that the respondents were far from the mean and to each other in their responses.

\section{Results}

The results of the study were obtained from the research questions answered and presented in Table 1 and Table 2.

\subsection{Research Questions 1}

What are planning techniques needed in the utilization of sensor technology for precision crop production?

Data for answering research question one were presented in Table 1.

Data in Table 1 revealed that 10 out of 17 items had their mean values ranged from 3.57 to 3.73. The values were within the real limit of $3.50-4.00$, indicating that the 10 items were highly needed in planning for the utilization of sensor technology for precision crop production. The table also showed that 6 of the items had their mean values ranged from 3.21 to 3.47. These values were within the real limit of $2.50-3.49$, indicating that the 6 items were averagely needed. One of the items had a mean value of 2.49 which is within the real limit of 1.50 to 2.49 , indicating that the item was slightly needed in planning for the utilization of sensor technology. Generally, all the 17 items were techniques needed in planning for utilization of sensor technology by farmers for precision crop production.

The standard deviation of all the 17 items ranged from $0.08-0.82$ which were below 1.96 . The values indicated that the respondents were close to the mean and to one another in their opinions.

\subsection{Research Questions 2}

What are operational techniques needed in the utilization of sensor technology for precision crop production? 
Table 1. Mean ratings of respondents on planning techniques needed in the utilization of sensor technology for precision crop production $\mathrm{N}=327$ (49 lecturers and 278 extension agents).

\begin{tabular}{ccccc}
\hline S/N & Items on planning techniques needed in the utilization of sensor technology & $\bar{x}$ & SD & Rm \\
\hline 1 & Acquire computer operation technique & 3.69 & 0.61 & HN \\
2 & Identify crop farm to be monitored & 3.21 & 0.76 & AN \\
3 & Identify agro-device allied information & 3.72 & 0.57 & HN \\
4 & Determine the number of sensory devices required per hectare & 3.58 & 0.82 & HN \\
5 & Determine plant density & 2.52 & 0.24 & AN \\
6 & Generate soil map with its characteristics & 3.47 & 0.50 & AN \\
7 & Create agro-electronic computer data base & 3.71 & 0.26 & HN \\
8 & Distribute sensory devices per hectare & 3.67 & 0.27 & HN \\
9 & Configure devises in the farm land & 3.45 & 0.13 & AN \\
10 & Set up base information for transmission of collected data & 3.73 & 0.09 & HN \\
11 & Connect sensor to any existing communication infrastructure (internet) & 2.71 & 0.12 & AN \\
12 & Identify relevant personnel & 3.57 & 0.08 & HN \\
13 & Procure relevant facilities for the project & 3.59 & 0.26 & HN \\
14 & Identify necessary adjustments to make for accurate data collection & 3.38 & 0.22 & AN \\
15 & Identify records to keep & 2.31 & 0.29 & HN \\
16 & Budget for the gadgets & 3.54 & 0.18 & HN \\
17 & Source for fund & 2.49 & 0.12 & SN \\
\hline
\end{tabular}

Note: Rm—Remark; HN—Highly Needed; AN—Averagely Needed; SN—Slightly Needed.

Table 2. Mean ratings of respondents on operation techniques needed in the utilization of sensor technology for precision crop production $\mathrm{N}=327$ (49 lecturers and 278 extension agents).

\begin{tabular}{|c|c|c|c|c|}
\hline $\mathbf{S} / \mathbf{N}$ & Item statement on operation techniques of sensor technology & $\bar{x}$ & SD & $\mathbf{R m}$ \\
\hline 1 & Calculate vegetation index (cover, growth and canopy) & 3.53 & 0.13 & $\mathrm{HN}$ \\
\hline 2 & Mount or attach sensory devices on the equipment & 3.45 & 0.28 & $\mathrm{AN}$ \\
\hline 3 & Drive ground-based mounted device & 3.80 & 0.47 & $\mathrm{HN}$ \\
\hline 4 & Issue appropriate command to remote sensor & 2.50 & 0.42 & AN \\
\hline 5 & Operate computer from home or strategic place & 3.87 & 0.14 & $\mathrm{HN}$ \\
\hline 6 & Control the devices during use & 3.74 & 0.56 & $\mathrm{HN}$ \\
\hline 7 & Manipulate the graphical user interface of the sensor technology & 3.64 & 0.14 & $\mathrm{HN}$ \\
\hline 8 & Monitor the crop yield & 2.87 & 0.91 & $\mathrm{AN}$ \\
\hline 9 & Control scenarios with graphical user interface & 3.23 & 0.75 & AN \\
\hline 10 & Record the observations or readings & 3.89 & 0.29 & $\mathrm{HN}$ \\
\hline 11 & Detach the device after use & 3.89 & 0.76 & $\mathrm{HN}$ \\
\hline 12 & Calculate vegetative index & 3.73 & 0.08 & $\mathrm{HN}$ \\
\hline 13 & Interpret data & 3.88 & 0.18 & $\mathrm{HN}$ \\
\hline 14 & Make suggestions based on interpreted data & 3.57 & 0.15 & $\mathrm{HN}$ \\
\hline 15 & Apply the data for crop production in specific areas of the farm & 3.65 & 0.39 & $\mathrm{HN}$ \\
\hline
\end{tabular}

Note: Rm—Remark; HN—Highly Needed; AN—Averagely Needed; SN—Slightly Needed.

Data for answering research question one were presented in Table 1.

Data in Table 2 revealed that 11 out of 15 items had their mean values ranged from 3.53 to 3.89 . The values were within the real limit of 3.50 - 4.00, indicating that all the 11 items were highly needed in operating sensor technology for precision crop production. The table also showed that 4 of the items had their mean values ranged from 2.50 to 3.45 . These values were within the real limit of $2.50-3.49$, indicating that the 4 items were averagely needed in operating sensory technology by farmers for precision crop production. Generally, all the 15 items were techniques needed in operating sensor technology by farmers for precision crop production.

The standard deviation of all the 15 items ranged from $0.14-0.91$ which were below 1.96 . The values indi- 
cated that the respondents were close to the mean and to one another in their opinions.

\section{Discussion of Result}

The result of the study in Table 1 revealed that in planning for utilization of sensor technology the farmers needed to acquire computer operation technique to collect route data to other sensors and back to external base station, determine the number of sensor devices required per hectare, determine the plant density, set up based information, configure and distribute sensor devises in the farm, connect sensor to any existing communication infrastructure (internet), identify crop farm to be monitored and agro-based allied information, relevant personnel, determine records to keep and provide necessary fund among others. The findings of this study were in line with the findings of [14] that the base station needs to be connected to an existing communications infrastructure or to the Internet where a user can have access to the reported data. The findings of the study were also in conformity with the findings of [11] who found out that configuration of different scenarios is necessary while [13] found out that sensor nodes when appropriately configured collect and route data either to other sensors or back to an external base station.

The result of the study in Table 2 revealed that in operating sensor technology, the farmer needed the techniques that could enable him calculate vegetation index (cover, growth and canopy), drive ground-based mounted device, issue appropriate command to remote sensor, manipulate the Graphical User Interface of the sensor, monitor the crop yield, interpret data and make suggestions among others. The findings of the study were in conformity with the findings of [11] that there is need to generate maps of the soil with its characteristics which included grid soil sampling ( $\mathrm{pH}$, moisture, electrical conductivity and temperature), yield monitoring, and crop scouting. The author further found out that strategically positioned sensors collect data in the form of electronic computer databases which gives birth to the Geographic Information System (GIS) for statistical analyses of data and determines variability of agricultural land with respect to its properties. The findings of the study were also in line with the findings of [10] that an effective method used to easily interpret remote sensing data is calculating vegetation indices.

The findings of the authors cited above helped to validation the results of this study.

\section{Conclusion}

It is the wish of farmers to produce enough to feed the teaming population without much stress despite the impact of climate change. This objective can only be achieved by the farmers through the use of sensory technologies for precision crop production. The problem is that most farmers lack the necessary techniques needed for effective manipulation of sensory technology in crop farming. Furthermore, the extension agents who educate the farmers on new technologies were also interested in making the farmers effective in crop production but the stepwise techniques on the utilization of sensor technology are not available for the teaching of farmers. It was based on this scenario that this topic emerged with the aim to identify the techniques needed by farmers in utilizing sensor technology for precision crop production as climate change adaptation strategy. This study identified 32 items that could be utilized by farmers in utilizing sensor technology in crop production as a coping strategy to climate change. The study therefore recommended that the extension agents should utilize the identified techniques in teaching farmers to make them become abreast with the needed techniques in utilization of sensor technology as adaptation strategy to climate change impacts. It was also recommended that farmers should make themselves available for the training to make them competent in guarding against climate change impact.

\section{References}

[1] Intergovernmental Panel on Climate Change (2007) Impacts, Adaptation and Vulnerability. Summary for Policymakers, in Climate Change: Contribution of Working Group II to the Fourth Assessment Report of the Intergovernmental Panel on Climate Change. Cambridge University Press, Cambridge.

http://www.ipcc.ch/pdf/assessment-report/ar4/syr/ar4 syr spm.pdf

[2] Idowu, A.A., Ayoola, S.O., Opele, A.I. and Ikenweiwe, N.B. (2011) Impact of Climate Change in Nigeria. Iranica Journal of Energy and Environment, 2, 145-152.

[3] Abdullah, A. and Barnawi, A. (2012) Identification of the Type of Agriculture Suited for Application of Wireless Sensor Networks. Russian Journal of Agricultural and Socio-Economic Sciences, 12, 19-36. 
[4] Karl, T.R., Melillo, J.M. and Peterson, T.C. (2009) Global Climate Change Impacts in the United States. United States Global Change Research Program. Cambridge University Press, New York.

[5] Treinish, L. (2013) Precision Farming Gains Global Foothold (Op-Ed). http://m.livescience.com/37400-smart-farming.html

[6] Metternicht, G. (2006) Use of Remote Sensing and GNSS in Precision Agriculture. Curtin University of Technology, Perth.

[7] Agri Food (2014) Applied Precision Crop Production. http://www.agrifoodatp.ac.uk/aatp/courses/crops/applied-precision-crop-production.aspx

[8] Tenkorang, F. and Lowenberg-DeBoer, J. (2008) On-Farm Profitability of Remote Sensing in Agriculture. The Journal of Terrestrial Observation, 1, 50-59.

[9] Alabama Cooperative Extension System (2014) Sensor Technology. http://www.aces.edu/anr/precisionag/Sensor_Tech.php

[10] Ortiz, B., Shaw, J. and Fulton, J. (2011) Basics of Crop Sensing. http://www.aces.edu/anr/precisionag/Sensor_Tech.php

[11] Sherine, M., Abd, E., Basma, M. and Mohammad, E. (2013) Precision Farming Solution in Egypt Using the Wireless Sensor Network Technology. Egyptian Informatics Journal, 14, 221-233. http://dx.doi.org/10.1016/j.eij.2013.06.004

[12] Aziz, A.A., Sekercioglu, Y.A., Fitzpatrick, P. and Ivanovich, M. (2012) A Survey on Distributed Topology Control Techniques for Extending the Lifetime of Battery Powered Wireless Sensor Networks. IEEE Communications Surveys and Tutorials, 15, 121-144. http://dx.doi.org/10.1109/SURV.2012.031612.00124

[13] Jagadeeswara, R.M., Suman, P.P. and Chenna, R.P. (2013) Homogeneous and Heterogeneous Energy Schemes for Hierarchical Cluster Based Routing Protocols in WSN: A Survey. Proceedings of the 3rd International Conference on Trends in Information, Telecommunication and Computing Lecture Notes in Electrical Engineering, 150, 591-595. http://dx.doi.org/10.1007/978-1-4614-3363-7_70

[14] Ilyas, M. and Mahgoub, I. (2005) Handbook of Sensor Networks: Compact Wireless and Wired Sensing Systems. CRC Press LLC, Florida.

[15] Idowu, A.A., Ayoola, S.O., Opele, A.I. and Ikenweiwe, N.B. (2011) Impact of Climate Change in Nigeria. Iranica Journal of Energy and Environment, 2, 145-152.

[16] Bruinsma, J. (2009) The Resource Outlook to 2050: By How Much Do Land, Water and Crop Yields Need to Increase by 2050? In: FAO Expert Meeting. How to Feed the World in 2050. Food and Agriculture Organization of the United Nations, Economic and Social Development Department, Rome, 2-16.

[17] Burney, J.A., Davis, S.J. and Lobell, D.B. (2010) Greenhouse Gas Mitigation by Agricultural Intensification. National Academy of Sciences, 107, 12052-12057.

[18] Food and Agricultural Organization (2011) Strengthening Capacity for Climate Change Adaptation in Agriculture: Experience and Lessons from Lesotho. FAO Report, Rome, 1-7. 
Scientific Research Publishing (SCIRP) is one of the largest Open Access journal publishers. It is currently publishing more than 200 open access, online, peer-reviewed journals covering a wide range of academic disciplines. SCIRP serves the worldwide academic communities and contributes to the progress and application of science with its publication.

Other selected journals from SCIRP are listed as below. Submit your manuscript to us via either submit@scirp.org or Online Submission Portal.
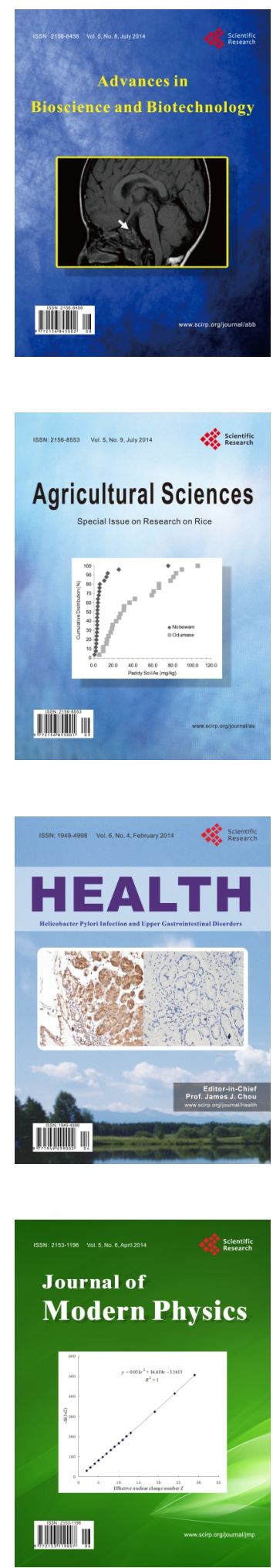
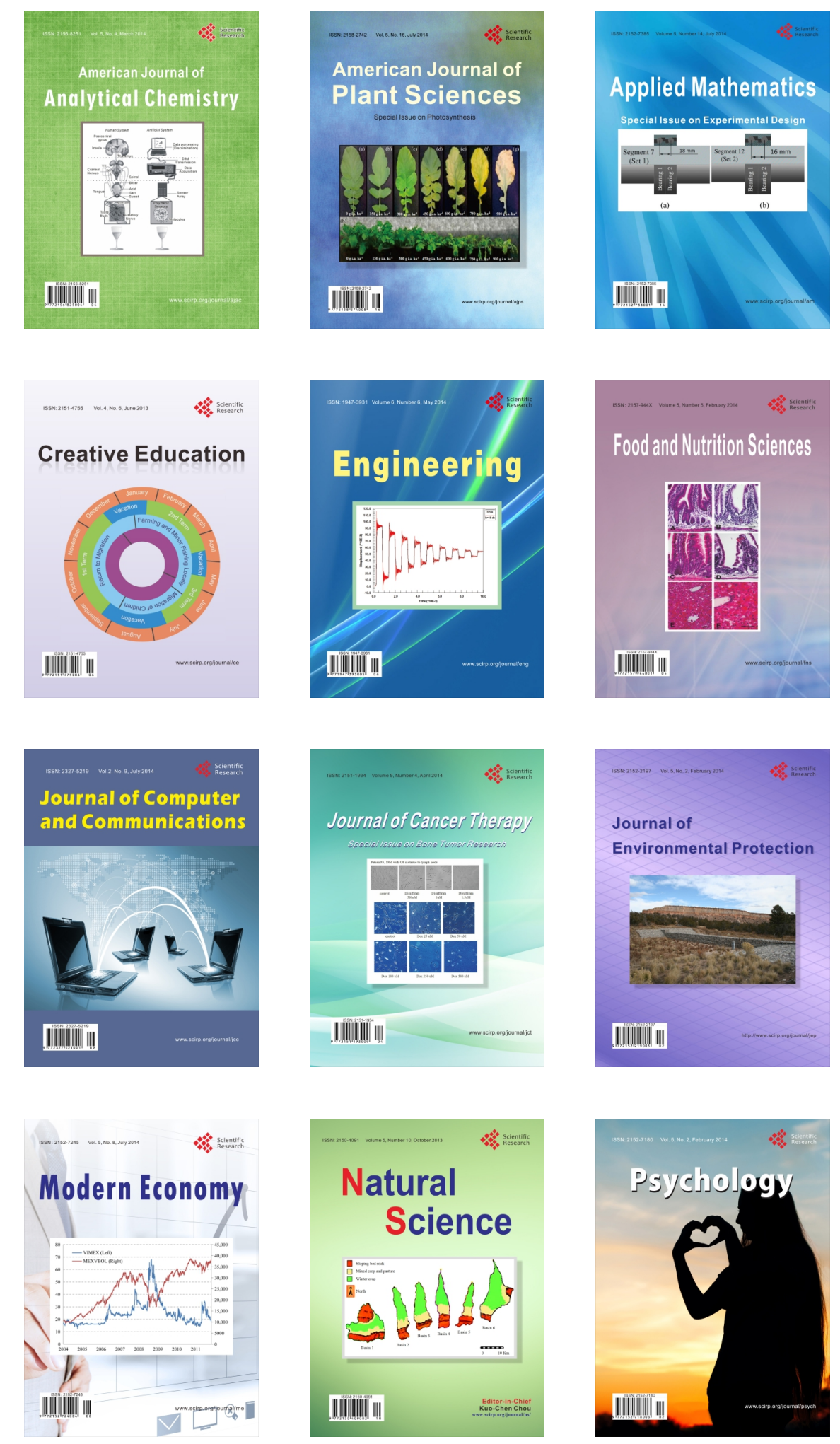